\title{
THE DEVELOPMENT OF LEAN HEALTHCARE MANAGEMENT SYSTEM (LHMS) FOR HEALTHCARE INDUSTRY
}

\author{
NURUL FADLY HABIDIN* \\ Department of Management and Leadership, Faculty of Management and Economics, Universiti Pendidikan Sultan Idris, 35900 Tanjung \\ Malim, Perak, Malaysia. Email: fadly@fpe.upsi.edu.my \\ Received: 19 July 2016, Revised and Accepted: 01 November 2016
}

\section{ABSTRACT}

Objective: The objective of this study was to identify lean healthcare management system (LHMS) constructs and to develop model to test the validity (exploratory [EFA] and confirmatory factor analysis [CFA]) of LHMS constructs for Malaysian healthcare industry.

Methods: Data were obtained from 238 healthcare managements in Malaysian healthcare industry. This report presents the results of the EFA, reliability analysis, and CFA which are empirically verified.

Results: A set of assessment measurement of LHMS constructs is expected to be suitable for characteristics and improves the competitiveness. The result shows that eight constructs of LHMS are acceptable in this study.

Conclusion: This research specifies a study which is based on the LHMS measurement includes leadership, employee involvement, organizational culture, customer focus, technological innovation, process innovation, managerial innovation, and healthcare performance. This study provides fundamental knowledge and direction for researchers in further research as well as practitioners to constantly improve performance through the implementation of LHMS.

Keywords: Lean healthcare, Healthcare performance, Healthcare industry, Malaysian.

(C) 2017 The Authors. Published by Innovare Academic Sciences Pvt Ltd. This is an open access article under the CC BY license (http://creativecommons. org/licenses/by/4. 0/) DOI: http://dx.doi.org/10.22159/ajpcr.2017.v10i2.14193

\section{INTRODUCTION}

Healthcare in Malaysia is mainly under the responsibility of the government's Ministry of Health. Malaysian healthcare system is divided into two sectors consisting of both a government healthcare system and private healthcare system. Healthcare is one of the 12 National Key Economics Areas under the $10^{\text {th }}$ Malaysia Plan (2011-2015). Contribution, and investment in healthcare industry expected to help the high-income nation of the year 2020 [1]. In addition, Malaysia has been continuously alert about the effective healthcare system. The increased number of medical schools showed that Malaysia is serious about providing quality healthcare, not only to the citizens but also to expatriates, tourists, migrants, and visitors.

Healthcare is one of the important parts that may influence Malaysian economy. Healthcare industry was concerned with a quality and efficiency to deliver a good service to their customers [2]. This is because the healthcare industry needs to deal with various problems such as increase demand for service, demographics, waiting time concern, rising cost of service delivery, government funding constraints, quality concerns, lack of quality personnel, and productivity [3]. According to the National Strategic Mission Thrusts [4], one of the objectives is productivity and innovation through K-economy. The researcher chose the healthcare industry because to achieve one of the objectives of the National Strategic Mission Thrusts to increase the productivity and innovation. Therefore, this study focused on lean healthcare management system (LHMS) in Malaysian healthcare industry.

LHMS is faced with challenges and opportunities from a rapidly changing operating environment, including increasing expectations on the quality of healthcare [5-8]. The lean concept originally developed in the automotive industry to deliver high-quality product and services while improving organizational performance and satisfying customers [9-11]. However, some organizations have begun adapting these concepts for the healthcare industry. Hagg et al. [12] stated that lean is an effective tool for identifying and eliminating waste from the process. The benefit and goal of applying lean in healthcare are to the best approach to reduce waste, as well as reducing wait times and unnecessary travel, while building quality, speed, and flexibility into the organization. Therefore, Malaysia needs to consider implements LHMS in providing better quality in the healthcare industry.

LHMS has been chosen as one of the strategies to overcome the issues. A service organization with global demands of service quality has paid attention to lean philosophies, principles, tools, and technique [13]. Recently, LHMS has received substantial interest in the healthcare industry. There has been an effort to study lean in healthcare industry $[14,15]$. LHMS in healthcare industry positively benefits for the patient, clinicians, and stakeholders [3,16], in addition detecting waste and eliminating waste [17-19]. Waste determines as a main principle in implementing lean. Thus, waste has been categorized into seven types, which are mistakes, over production, over processing steps, employee movement, transportation, waiting time, and services which do not meet customer need.

Waste in healthcare unit occurs such as delays between the expected time and the actual time for a visit, operation, over capacity, preparation time needed consists of operational, visit, medical device time, and procedures to manage referrals [20]. According to Habidin et al. [21], healthcare industries have moved forward to focus on efficiency especially on preparing lower cost material, cheaper price, JIT deliveries and elimination of waste, and defects in many aspects of the activity operation. Vlachos and Bogdanovic [19] also supported that LHMS is not only simply to reduce waste but also can add value offered to customers. 
LHMS has been selected in this study to see the potential in Malaysia healthcare industry. LHMS is a tool for quality improvement which has been used by many organizations. It is suitable for service industry because lean improves the speed of delivery, quality, and flexibility [22]. Other than that LHMS is used by healthcare organization to reduce waste and medical error [23-26] and give added value for the customer. Reductions in errors can give high benefits in terms of time, cost, patient welfare, staff motivation, and productivity. Thus, LHMS is an important practice that can be implemented in Malaysian healthcare industry to increase the healthcare performance. Based on that issue, healthcare sector should be adopted LHMS for assessing an organization to achieve the performance. Healthcare industry may concern about critical issues such as medical error, patient safety, quality, efficiency, and medical cost.

To increase the healthcare performance, this study focused on LHMS implementation in Malaysian healthcare industry. Malaysian healthcare industry can implement LHMS to achieve the success and sustain the quality improvement of the healthcare industry. Therefore, the objectives of this paper are to identify LHMS constructs and to develop model to test the validity (exploratory [EFA] and confirmatory factor analysis [CFA]) of LHMS constructs for Malaysian healthcare industry.

\section{METHODS}

\section{Questionnaire development}

The questionnaire that has been constructing consists of general information and LHMS measurement (Leadership [LP], employee involvement [EI], organizational culture [OC], customer focus [CF], technological innovation [TI], process innovation [PI], managerial innovation [MI], and healthcare performance [HP]). The summary of survey questionnaire design is shown in Table 1.

\section{Respondent profile descriptive statistic}

The profile of the respondents from the hospital in Malaysia is shown in Table 2. There are 238 respondents who are attached to the healthcare industry. There are five questionnaires, and the question consists of types of ownership, number of employees, quality systems certification, current position, and period of current position.

From the survey, the types of ownership showed that the majority of the respondents involved are fully owned by Malaysians (64.29\%), followed by venture companies $(25.63 \%)$, and the minority were owned by foreigners $(10.08 \%)$.

In addition, the survey also asked about the number of employees for each hospital. The results showed that the percentage for the hospital which had more than 300 employees was $49.58 \%$. Meanwhile, the number of employees for $151-300$ was $23.11 \%$. The number of employees for $50-150$ was $20.59 \%$ and the number of employees which had $<50$ was $6.72 \%$.

In the aspect of involvement in certified quality system standard, both of these certifications are an important and major requirement for the hospital which is involved in the healthcare industry. Meanwhile, the $92.44 \%$ of the respondents were certified by ISO 9001:2008. For others, certification was $8.40 \%$.

The response in the aspect of current position also is very important for this survey. The high acceptance from the top and middle management contributes toward the authenticity and validity of responses given and emphasizes the importance of quality in an organization. According to Table 2, 39.08\% of the respondents held senior management posts and the rest held middle management post (50.42\%). Meanwhile, others' current position was $10.50 \%$

Regarding the current position (year) among the respondents, some of them held the position for $<1$ year (13.45\%), a majority held the position for $1-3$ years $(17.65 \%)$, and the position for 3-6 years was $26.05 \%$. A percentage (42.86\%) held the position for more than 6 years.

\section{Population and sampling}

In this study, samples were selected from the list of hospital in Malaysian healthcare industry. To achieve the research objectives, the selection of the Malaysian healthcare industry was done by data contained in public and private healthcare in Malaysia. Healthcare industries are chosen as the population of study because organizations in this industry are exposed to the risk of defects that could endanger customers, especially patients. Besides, the quality and safety of the services are essential for a healthcare organization to survive [27]

The representative of respondent is very critical because the data give the impression of statistical characteristic of the population. There are currently 123 hospitals that are members of the Association of Private Hospital of Malaysia represented as population in this study [28]. Researcher will send three sets of questionnaire to each hospital, and the total will become 369 respondents. In this study, 238 respondents from healthcare management were selected.

\section{Reliability analysis}

Reliability test is the most frequently used in empirical studies for assessing the internal consistency, and it is verified using Cronbach's Alpha Coefficient [29]. In this study, Cronbach's Alpha was used to assess reliability for each construct (LP, EI, OC, CF, TI, PI, MI, and HP) to measure the internal consistency and indicate how different items can reliably measure the construct. This alpha value ranges from 0 to 1 , which means higher value indicates higher levels of internal consistency.

\section{Validity analysis}

Validity is defined as steps for measuring the instrument in the study. James [30] argues that validity of a measurement instrument is the extent to which the instrument measures what it is supposed to measure.

To meet the requirement of specifying the measurement model and identifying the indicator measuring each construct, factor analysis was conducted. First, the EFA was used to identify tentative items, as well as to suggest items for deletion and places where item should be added. Conducting EFA on a single summated scale indicated whether all items within the summated scale load on the same construct or whether the summated scale actually measures more than one construct. At this stage, convergent validity was tested in which for each construct, item loading higher than 0.4 was accepted [31].

Second, factor analysis was the confirmation on developed factors or constructs. In this study, the CFA was conducted based on a step which is multiple factor first order confirmatory. CFA is the most comprehensive method to test and examine how well the data set fits the measurement

Table 1: Summary of survey questionnaire design

\begin{tabular}{llll}
\hline Section & Topic & Number of question, constructs, and items & Question/Likert scale \\
\hline 1 & General information & 5 questions & $\begin{array}{l}\text { Types of ownership, number of employees, quality systems } \\
\text { certification, current position, and period of current position }\end{array}$ \\
2 & LHMS & 8 constructs and 49 measurement items & 7 Likert scale:[7] Very High to[1] very low \\
\hline
\end{tabular}

LHMS: Lean healthcare management system 
structure. The next stage in the analysis was to test the measurement model, in which the LP, EI, OC, CF, TI, PI, MI, and HP were tested.

\section{Statistical analysis}

In this study, the survey instrument was analyzed using two packages statistical software. First, the Statistical Package for Social Sciences (SPSS) for window Version 21.0 was used to perform the required statistical analysis of the data from surveys. Second, the SEM Version 21.0 was used. In general, analysis of moment structures (AMOS) 21.0 has been selected to perform the SEM analysis. AMOS uses the basic overall goodness-of-fit measures to assess the compatibility of the proposed model with the observable data. The general model of goodness-of-fit is assess using the following six criteria: Chi-square over degrees of freedom (X2/df), goodness of fit index (GFI), Adjusted

Table 2: The profile of the respondent $(n=238)$

\begin{tabular}{ll}
\hline Constructs/measures & Frequency (\%) \\
\hline Types of ownership & \\
100\% local & $153(64.29)$ \\
100\% foreign & $24(10.08)$ \\
Joint venture & $61(25.63)$ \\
Number of employees & \\
$<50$ & $16(6.72)$ \\
Between 50 and 150 & $49(20.59)$ \\
Between 151 and 300 & $55(23.11)$ \\
More than 300 & $118(49.58)$ \\
Company certified to quality system standard & \\
IS0 9001:2008 & $220(92.44)$ \\
None & $0(0.00)$ \\
Others & $20(8.40)$ \\
Current position & \\
Senior management & $93(39.08)$ \\
Middle management & $120(50.42)$ \\
Others & $25(10.50)$ \\
Current position (years) & \\
<1 year & $32(13.45)$ \\
1-3 years & $42(17.65)$ \\
3-6 years & $62(26.05)$ \\
More than 6 years & $102(42.86)$ \\
\hline Some companies have more than one certification &
\end{tabular}

Table 3: KMO and Bartlett's test for LHMS constructs

\begin{tabular}{ll}
\hline KMO and Bartlett's test & \\
\hline KMO measure of sampling adequacy & 0.940 \\
Bartlett's test of sphericity & \\
Approx Chi-square & $1.211 \mathrm{E} 4$ \\
df & 1176 \\
Significant & 0.000 \\
\hline LHMS: Lean healthcare management system, KMO: Kaiser-Meyer-Olkin
\end{tabular}

GFI (AGFI), comparative fit indexes (CFI), tucker Lewis index (TLI), and root mean square error approximation (RMSEA)

\section{RESULTS}

EFA

This section consists of the interpretation about EFA for the LHMS constructs. For this study, EFA was conducted in the EFA of LHMS constructs.

\section{EFA on LHMS constructs}

EFA with varimax rotation of 49 items of LHMS was done on a random sample $(n=238)$ of Malaysian healthcare industry to determine the basic details of each LHMS constructs, namely: LP, EI, OC, CF, TI, PI, MI, and HP. The Kaiser-Meyer-Olkin (KMO) and Bartlett's Test for LHMS is shown in Table 3. The KMO analysis showed the sampling adequacy as 0.940 , which was more than 0.7 , indicating that it was suitable for principal component analysis. Similarly, Bartlett's test of sphericity was significant at $\mathrm{p}<0.001$, indicating that there was sufficient correlation among the items to proceed with the analysis.

\section{Total variance explained}

Eight factors in the initial solution which had larger Eigenvalues from unity are shown in Table 4. These eight factors contributed $79.367 \%$ from the total variance and were sufficient for further analysis which required at least 50\% [32]. This indicates that eight latent influences were associated. Meanwhile, the last column of cumulative percentage showed that the variance explained by extraction solution was also $79.367 \%$, similar to the initial solution.

\section{Rotated component matrix results}

The function of rotated component matrix assists the researcher to determine what represents the component and identify items which correlate the highest to one factor and on the lowest remaining factor. In EFA, the discriminant validity is shown when the item loading is high toward the related factor when compared to other factors. Thus, the minimum load for each item of at least 0.5 to various factors is considered sufficient [33].

For this study, there were eight factors for LHMS constructs. The first factor was made up of the six items from LP building, including LP1, LP2, LP3, LP4, LP5, and LP6. The second factor was classified as EI with six items (EI1, EI2, EI3, EI4, EI5, and EI6). The third item was classified as OC with five items (OC1, OC2, OC3, OC4, and OC5). One item was suggested to be removed (OC6). Fourth, CF was categorized with six items (CF1, CF2, CF3, CF4, CF5, and CF6). Fifth, TI with five items (TI1, TI2, TI3, TI4, and TI5). Next, PI with five items (PI1, PI2, PI3, PI4, and PI5). For MI, MI with five items (MI1, MI2, MI3, MI4, and MI5). Finally, HP with 11 items (HP1, HP2, HP3, HP4, HP5, HP7, HP8, HP9, HP10, HP11, and HP12). Two items were suggested to be removed (HP6 and HP13). After the analysis of items, the result of EFA showed that 49 items of LHMS constructs were not removed.

Table 4: Results of total variance explained for LHMS

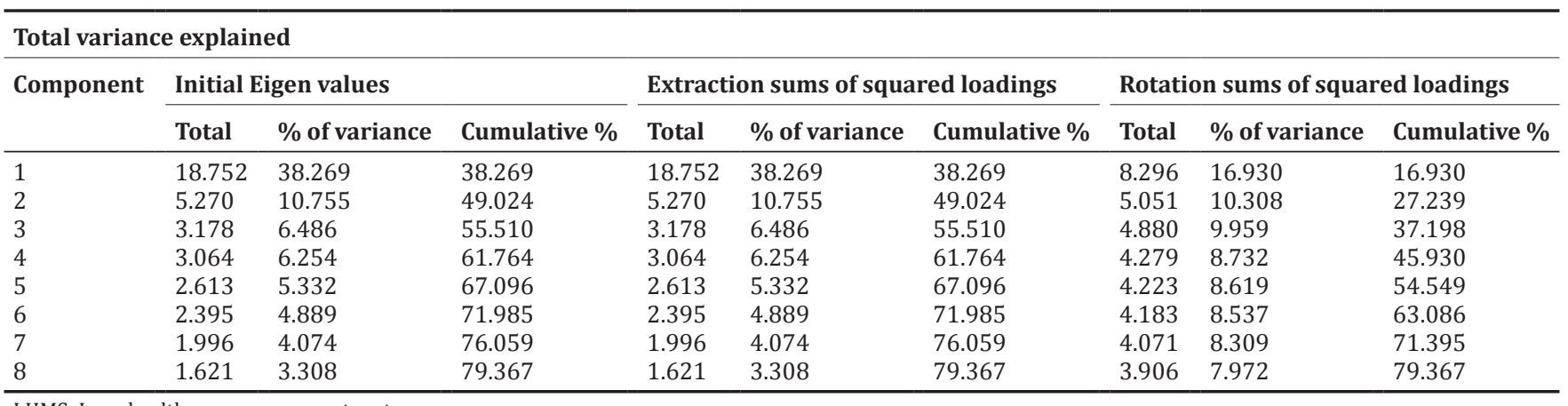

LHMS: Lean healthcare management system 


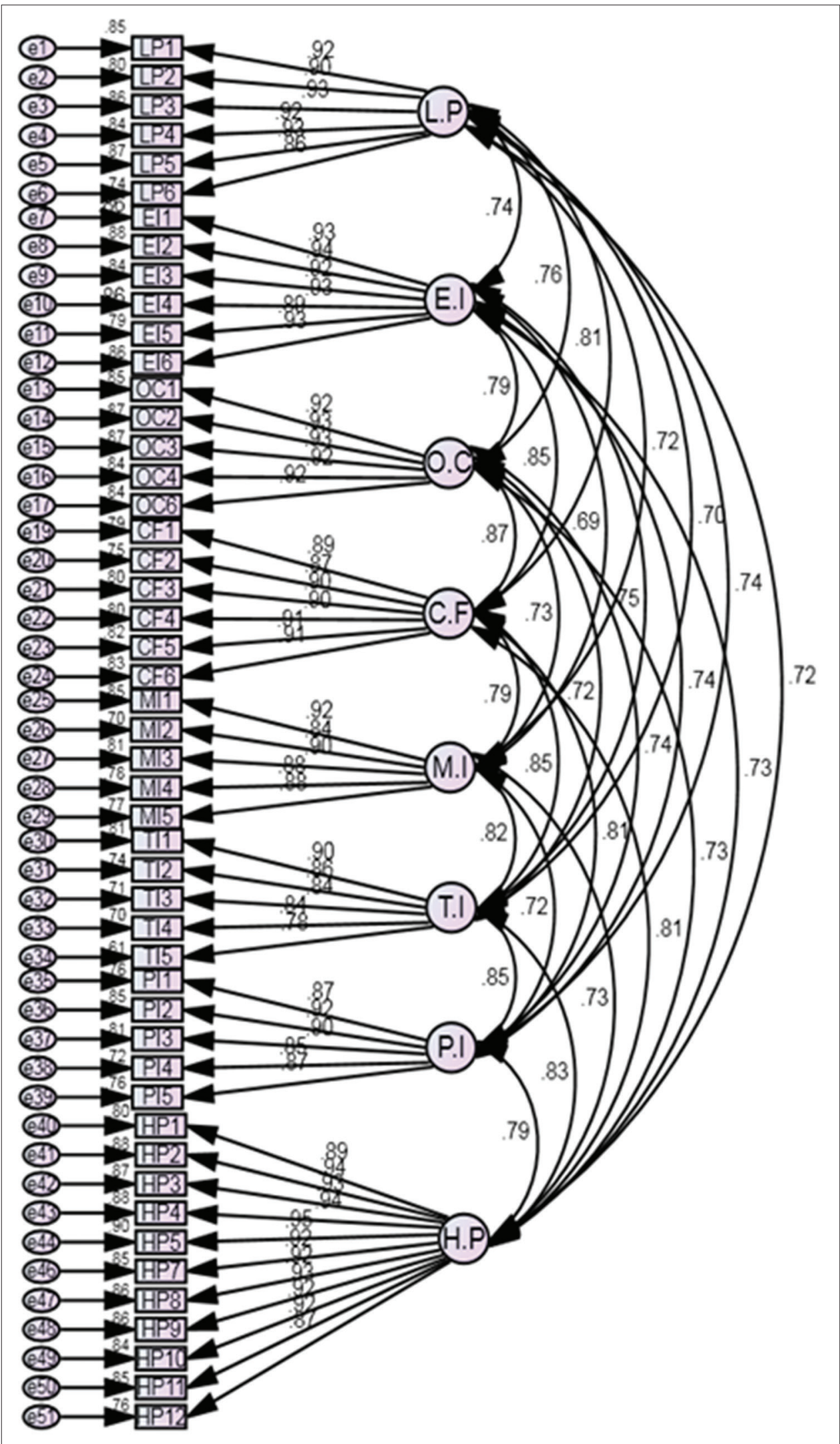

Fig. 1: The output path diagram for eight factors of lean healthcare management system model

Reliability analysis

For this study, the reliability was analyzed using SPSS reliability analysis for all items of LHMS. The latter method was implemented, and the internal consistency was conducted on 49 items for LP, EI, OC, CF,
TI, PI, MI, and HP. The value of alpha must be at least $>0.6$, indicating that the reliability values of the each construct and measure were received [30]. Table 5 presented the summary of the analysis result of reliability analysis. 
Table 5: Results of reliability analysis for LHMS constructs

\begin{tabular}{|c|c|c|c|c|}
\hline $\begin{array}{l}\text { Constructs/ } \\
\text { measures }\end{array}$ & $\begin{array}{l}\text { Number } \\
\text { of items }\end{array}$ & $\begin{array}{l}\text { Alpha }(\alpha) \\
\text { values }\end{array}$ & $\begin{array}{l}\text { Item for } \\
\text { deletion }\end{array}$ & $\begin{array}{l}\text { Alpha }(\alpha) \\
\text { if item is } \\
\text { deleted }\end{array}$ \\
\hline \multicolumn{5}{|l|}{ LHMS } \\
\hline Leadership & 6 & 0.958 & None & 0.958 \\
\hline $\begin{array}{l}\text { Employee } \\
\text { involvement }\end{array}$ & 6 & 0.956 & None & 0.956 \\
\hline $\begin{array}{l}\text { Organizational } \\
\text { culture }\end{array}$ & 5 & 0.953 & None & 0.953 \\
\hline Customer focus & 6 & 0.890 & None & 0.890 \\
\hline $\begin{array}{l}\text { Technological } \\
\text { innovation }\end{array}$ & 5 & 0.945 & None & 0.945 \\
\hline $\begin{array}{l}\text { Process } \\
\text { innovation }\end{array}$ & 5 & 0.953 & None & 0.953 \\
\hline $\begin{array}{l}\text { Managerial } \\
\text { innovation }\end{array}$ & 5 & 0.958 & None & 0.958 \\
\hline $\begin{array}{l}\text { Healthcare } \\
\text { performance }\end{array}$ & 11 & 0.960 & None & 0.960 \\
\hline Total & 49 & & & \\
\hline
\end{tabular}

LHMS: Lean healthcare management system

The analysis result showed that all the constructs and measures for this study were accepted because the value of alpha was $>0.6$. This means that all the items were reliable and accepted for further analysis.

\section{CFA}

CFA is to measure as specified by a multiple-indicator measurement model for LHMS. The model was tested which after the measurement model was analyzed and accepted, indicating that the construct can be used to proceed with the structural model testing. This section is known as the measurement model test for LP, EI, OC, CF, TI, PI, MI, and HP which were tested by using the confirmatory model and confirmed for evaluating construct validity using the maximum likelihood method with multiple factors.

\section{LHMS constructs with eight factors}

The first tested model demonstrated for the LHMS constructs consisted of LP, EI, OC, CF, TI, PI, MI, and HP. LHMS model with eight factors manifested an adequate fit outcome as shown in Fig. 1. $\chi^{2}$ statistics was 1960.294 (degree of freedom $=1099, \mathrm{p}<0.001$ ), with a ratio of $\chi^{2} / \mathrm{df}$ value being $1.784<2.0$, thus exhibiting a good fit. The GFI was 0.764 and AGFI was 0.737 which was moderate fit. The CFI was 0.948 ; the TLI was 0.944 . The score, which was greater than 0.9 , indicated an excellent fit. The value of (RMSEA) was $0.058<0.08$, thus displaying a good fit. All canonical correlation $(\mathrm{rc})$ showed values of $<1.0$, signaling that the discriminant validity was tested and acceptable.

At factor loading, the standard coefficient estimated at 0.837 (MI2) and 0.950 (HP5) was good as it surpassed the accepted level of 0.3 with $\mathrm{p}<0.001$. With that it is suggested that these eight constructs were applicable for measuring the LHMS.

\section{DISCUSSION}

The measurement model was evaluated in this study to ensure the validity of latent variables in LP, EI, OC, CF, TI, PI, MI, and HP. By using the AMOS 21.0 software to test this model, it was found that there were a few valuable findings which can be mentioned.

Through the measurement model of LHMS, eight factors of model analysis as measurement model for LHMS constructs demonstrated a good fit and proved that this model is valid and reliable for the Malaysian healthcare industry. The results of the study indicated that the latent variables of LHMS were valid and reliable. The result of the study proved that LHMS for LP, EI, OC, CF, TI, PI, MI, an HP was valid and reliable. For LP, the result had 6 items, EI with 6 items, OC with 5 items, CF with 6 items, TI with 5 items, PI with 5 items, MI with 5 items, and HP with 11 items. All the factors were acceptable in this study. Therefore, the results will be beneficial for Malaysian healthcare industry to improve the performance.

\section{CONCLUSION}

This research specifies a study which is based on the LHMS measurement including LP, EI, OC, CF, TI, PI, MI, and HP. The key contributions of this research are listed as follows: For LP, the result had 6 items, EI with 6 items, OC with 5 items, CF with 6 items, TI with 5 items, PI with 5 items, MI with 5 items, and HP with 11 items were developed and verified. Empirical test results prove that the presence of LHMS can improve the HP. Finally, the final result of this research is reliable in terms of the decision-making process in healthcare evaluation through the implementation of LP, EI, OC, CF, TI, PI, MI, and HP for Malaysian healthcare industry. Thus, the impact of LP, EI, OC, CF, TI, PI, MI, and HP will help the practitioners, researcher, and academicians in improving the performance, especially in Malaysian healthcare industry.

\section{ACKNOWLEDGMENT}

The researches would like to acknowledge the Ministry of Higher Education for the financial funding of this research through Exploratory Research Grant Scheme, and Research Management Centre, UPSI for Research University Grant.

\section{REFERENCES}

1. Malaysian-German Chamber of Commerce and Industry, (MGCC), National Key Economics Areas, (NKEA); 2011. Available from: http:// www.malaysia.ahk.de/en/.

2. Khan SN, Joseph S, Sasidharan P. A study of clinical pharmacist initiated intervention for the optimal use of medications in a neonatal intensive care unit (Nicu) of a tertiary care hospital, South India. Int J Pharm Pharm Sci 2016;8(1):23-6.

3. Villeneuve C. Lean healthcare in Canada. Sci Tech J 2011;47(1):41-8.

4. National Strategic Mission Thrusts. The National Mission Trust; 2014. Available from: http://www.moh.gov.my/.

5. Shazali NA, Habidin NF, Ali N, Khaidir NA, Jamaluddin NH. Lean healthcare practice and healthcare performance in Malaysian healthcare industry. Int J Sci Res Publ 2013;3(1):1-5.

6. Habidin NF, Shazali NA, Ali N, Khaidir NA, Jamaludin NH. Exploring lean healthcare practice and supply chain innovation for Malaysian healthcare industry. Int J Bus Exc 2014;7(3):394-410.

7. Habidin NF, Ali N, Janudin SE, Salleh MI, Latip NA, Azman MN. Areview of service quality improvement and organizational performance in healthcare industry. Int J Pharm Sci Rev Res 2015a;35(2):144-50.

8. Habidin NF, Ali N, Khaidir NA, Shazali NA, Jusoh O. Relationship between customer relationship management, service quality improvement and organizational performance in Malaysian healthcare industry. Int J Innov Sci Res 2015b;14(2):293-302.

9. Leslie M, Hagood C, Royer A, Reece CP Jr, Maloney S. Using lean methods to improve OR turnover times. AORN J 2006;84:849-55.

10. Ali N, Habidin NF, Jamaludin NH, Khaidir NA, Shazali NA. Customer relationship management and organizational performance in Malaysian healthcare industry. Int J Adv Res Technol 2013;2(1):1-5.

11. Habidin NF, Khaidir NA, Shazali NA, Ali N, Jamaludin NH. The development of process innovation and organizational performance in Malaysian healthcare industry. Int J Bus Innov Res 2015c;9(2):148-62.

12. Hagg H, Suskovich D, Workman J, Scachitti S, Hudson B. Adaption of lean methodologies for healthcare applications. RCHE Pub 2007; 24(1):1-8

13. Lianga OA, Subramaniam P, Paraidathathuc T. Membership rate, perception and awareness of their professional association among newly licensed pharmacists. Int J Pharm Pharm Sci 2015;7(2):48-51.

14. Papadopoulas T. Continuous improvement and dynamic actor associations. Lead Health Serv 2011;24(3):207-27.

15. Yousri TA, Khan Z, Chakrabarti D, Fernandes R, Wahab K. Lean thinking: Can it improve the outcome of fracture neck of femur patients in a direct general hospital? Injury 2011;42(11):1234-7.

16. Alsmadi M, Almani A, Jerisat R. A comparative analysis of lean practices and performance in the UK manufacturing and service sector firms. Total Qual Manage Bus Exc 2012;23(3-4):381-96.

17. Carney M. Influence of organizational culture on quality healthcare 
delivery. Int J Health Care Qual Assur 2011;24:523-39.

18. Vlachos I, Bogdanovic A. Lean thinking in the European hotel industry. Int J Tour Manage 2012;31(1):1-10.

19. Roslan MH, Habidin NF, Zainudin MZ, Norazlan AN. Waste management practices and organization performance in Malaysian healthcare industries. J Appl Sci Res 2014;2(2):14-22.

20. Kollberg B, Dahlgaard JJ, Brehmer P. Measuring lean initiatives in health care services: Issues and findings. Int J Prod Perform Manage 2007;56(1):7-24

21. Habidin NA, Omar CM, Ibrahim N. Confirmatory factor analysis for lean healthcare practices in Malaysian healthcare industry. J Control Issues Thought 2012;2(1):17-26.

22. Snyder KD, McDermott M. A rural hospital takes on lean. J Health Qual 2009;31(3):23-8

23. Jimmerson C, Weber D, Sobek DK $2^{\text {nd }}$. Reducing waste and errors: Piloting lean principles at Intermountain Healthcare. Jt Comm J Qual Patient Saf 2005;31:249-57.

24. Dickson EW, Singh S, Cheung DS, Wyatt CC, Nugent AS. Application of lean manufacturing techniques in the Emergency Department. J Emerg Med 2009:37:177-82

25. Khaidir NA, Habidin NF, Ali N, Shazali NA, Jamaluddin NH. Six sigma practices and organizational performance in Malaysian healthcare industry. IOSR J Bus Manage 2013;6(5):29-37.
26. Norazlan AN, Habidin NF, Roslan MH, Zainudin MZ. Investigation of kaizen blitz and sustainable performance for Malaysian healthcare industry. Int J Qual Innov 2014;2(3/4):272-84.

27. Chen SJ, Pan FF, Chen HC. Integrating six-sigma and healthcare quality improvement circles in reducing the needle sticking. Glob J Bus Res 2008;2(2):87-95.

28. Annual Report KPJ Healthcare Berhad; 2011. Available from: http:// www.bursamalaysia.com/.

29. Cronbach LJ. Coefficient alpha and the internal structure of tests. Psychometrika 1951;16:297-334

30. James L. A study on corporate social responsibility practices in relation to organizational culture and business ethics in information technology industry in Bangalore city (Unpublished doctoral dissetation). Department of Business Administration 2012; Bharathidasan University.

31. Hair JF, Ringle CM, Sarstedt M. PLS-SEM: Indeed a silver bullet. J Mark Prac 2011;19(2):139-51.

32. Zakuan NM. Structural Analysis of Total Quality Management, ISO/TS 16949 and Organizational Performance in Malaysian and Thailand Automotive Industry (Unpublished Doctoral Dissertation). Faculty of Mechanical Engineering, Universiti Technology Malaysia; 2009

33. Nunnaly J. Psychometric Theory. New York: McGraw-Hill; 1978. 